\title{
EFEITO RESIDUAL DA ESCÓRIA DE SIDERURGIA COMO CORRETIVO DE ACIDEZ DO SOLO NA SOQUEIRA DE CANA-DE-AÇÚCAR ${ }^{(1)}$
}

\author{
R. M. PRADO ${ }^{(2)}$, F. M. FERNANDES ${ }^{(3)} \&$ W. NATALE ${ }^{(4)}$
}

\begin{abstract}
RESUMO
A escória de siderurgia, como material corretivo e efeito residual prolongado, pode beneficiar culturas de ciclo longo, a exemplo da cana-de-açúcar, minimizando a queda de produção ao longo do ciclo produtivo. Este trabalho objetivou avaliar diferentes níveis de saturação por bases, utilizando, como corretivo do solo, a escória de siderurgia, comparando-a com calcário calcítico, nas alterações de alguns atributos químicos do solo, bem como na resposta da soqueira da cana-de-açúcar. Para isto, realizou-se um experimento com a variedade SP 80-1842, durante o terceiro e o quarto corte, nos anos agrícolas 2000/01 e 2001/02. Os tratamentos, dispostos em blocos casualizados, em esquema fatorial com quatro repetições, constaram de duas fontes de corretivos, calcário calcítico e escória de siderurgia, e quatro níveis de correção, estimados pelo método da saturação por bases (V \%): testemunha (sem correção) e com correção para V \% de 50; 75 e 100, tendo sido tais corretivos aplicados na época do plantio da cana-de-açúcar. $O$ calcário calcítico e a escória de siderurgia promoveram efeito residual benéfico, após $\mathbf{4 8}$ meses da aplicação, na correção da acidez do solo e na elevação do valor da saturação por bases; a maior dose de calcário causou efeito depressivo no perfilhamento, no número de colmos industrializáveis e na produção da cana-de-açúcar, fato não observado com uso da escória de siderurgia; a aplicação da escória de siderurgia e do calcário, em pré-plantio, promoveu efeito residual positivo na produção da soqueira de cana-de-açúcar.
\end{abstract}

Termos de indexação: silicato de cálcio, calcário calcítico, saturação por bases, Saccharum.

\footnotetext{
(1) Recebido para publicação em dezembro de 2001 e aprovado em setembro de 2002.

(2) Doutorando em Produção Vegetal do Departamento de Sol os e Adubos, Faculdade de Ciências Agrárias e Veterinárias - UNESP. Via de Acesso Prof. Paulo Donato Castellane, s/n, CEP 14870-000 J aboticabal (SP). E-mail: rmprado@fcav.unesp.br

(3) Professor Adjunto, Departamento de Fitossanidade, Engenharia Rural eSol os, Faculdade de Engenharia deIIha Solteira - UNESP. Caixa Postal 31, CEP 15385-000 IIha Solteira (SP).

(4) Professor Adjunto, Departamento de Solos e Adubos, Faculdade de Ciências Agrárias e Veterinárias, UNESP.
} 


\title{
SUMMARY: RESIDUAL EFFECT OF CALCIUM SILICATE SLAG AS SOIL ACIDITY CORRECTIVE IN SUGAR CANE RATTOON
}

\begin{abstract}
Calcium silicate slag, as a soil acidity corrective material with long-lasting residual effects, can benefit long-cycle cultures like sugar cane, thus minimizing production drops during theproductivecycle. This study evaluated different basesaturation levels, comparing calcitic limestone to basic slag as a soil corrective agent, in relation to alterations of some chemical soil properties, as well as to the response of sugar canerattoon. Sugar cane of the SP 80-1842 type, during the third and fourth cut in the agricultural years 2000/ 01 and 2001/ 02, was used for the experiment. The treatments, arranged in randomized blocks with four replications, consisted in theapplication of two correcti veagents: cal citic limestone and basic slag, evaluated by the base saturation method, with four correcti on levels ( $\mathrm{V} \%$ ): control (without correction), correction for $\mathrm{V} \%$ to 50; 75; and 100, applied at planting. After 48 months, both calcitic limestone and basic slag had generated a beneficial residual effect in thecorrection of soil acidity and theincrease of basesaturation. Thehighest limestone rate caused a restrictive effect on the sprouts, the number of industrial ly usableculms and on the sugar cane yied, while under the use of basic slag, this fact was not observed. The application of basic slag and limestone in preplanting caused a positive residual effect on the yield of sugar canerattoon.
\end{abstract}

Index terms: calcium silicate, cal citic limestone, base saturation, Saccharum.

\section{INTRODUÇÃO}

A calagem promove a neutralização do Al tóxico na camada arável (Orlando Filho et al., 1990), bem como em subsuperfície (Prado et al., 1998), possibilitando a proliferação intensa das raízes, com reflexos positivos no crescimento da cana-de-açúcar.

No estabel ecimento de cultura semi perene, como a cana-de-açúcar, a calagem adequada éimportante, visto que um solo ácido comprometerá a produtividade das plantas por muito tempo (Raij et al., 1996). Este fato torna-se importante, porque a calagem superficial em lavouras em soqueiras exerce ação restrita na neutralização da acidez do solo em profundidade e sem efeito significativo na produção (Salata et al., 1995). U ma adequada utilização da prática da calagem, com maior relação benefício/ custo, requer atenção não só no ano agrícola de sua aplicação, mas também em anos sucessivos, isto é, em seu efeito residual, beneficiando todo o ciclo das soqueiras, com maior longevidade e com aumento do intervalo entre as reformas do canavial.

U ma das alternativas para corrigir os solos ácidos seria o uso da escória de siderurgia, um resíduo da indústria do aço e ferro-gusa, constituída quimicamente de um silicato de cálcio $\left(\mathrm{CaSiO}_{3}\right)$ (Amaral et al., 1994) com propriedade corretiva da acidez do solo semel hante à do calcário (Ribeiro et al., 1986). Entretanto, a escória apresenta liberação mais lenta de nutrientes, quando comparada ao cal cário, em solo cultivado com cana-de-açúcar em vasos (Prado \& Fernandes, 2000a). No Hawai, Khalid et al. (1978) aplicaram um silicato em diferentes condições de acidez do solo $(\mathrm{pH}=5,5 ; 6,0$ e 6,5) em sistema de rotação de culturas (cana-deaçúcar, milho e capim-desmodium). Os autores constataram que houve efeito residual significativo do silicato no solo (teores de Si), após 56 meses, sendo maior na dose mais el evada.

É possível queo maior efeito residual dos silicatos no solo, com o uso da escória, seja devido a um equilíbrio químico, ou seja, com a solubilização da escória, obtém-se um incremento inicial do valor $\mathrm{pH}$ e da concentração de Ca. E sse aumento pressupõe decréscimos na dissolução da escória, uma vez que a solubidade desse material em solução aquosa diminui com o aumento do pH e da concentração de Ca da solução (Kato \& Owa, 1996).

Saliente-se que a escória de siderurgia é, atualmente, pouco usada na agricultura brasileira, contrariamente ao que ocorre nos Estados Unidos, J apão e China. Na literatura nacional, existem alguns trabal hos que tratam do uso desse resíduo como corretivo deacidez esua rel ação com a resposta das culturas, especialmente as anuais, como arroz, sorgo e milho (Prado et al., 2001). Segundo esses autores, em culturas semi perenes, como a cana-deaçúcar, inexistem pesquisas em condi ções de campo, em todo cicl o de produção (cana-planta e soqueiras), embora existam indicações favoráveis de aplicação desse resíduo no desenvolvimento inicial da canade-açúcar (1ㅇe 2o corte) (Prado \& Fernandes, 2001b).

A cana-de-açúcar apresenta considerável potencial de resposta quanto à produção de açúcar e álcool, a partir do uso da escória de siderurgia, a exemplo do que ocorre na região da Flórida nos Estados Unidos (Elawad et al., 1982; Anderson et al., 1987; Anderson et al., 1991). Além dos benefícios 
às culturas, existe a possibilidade da reciclagem de grande parte desse resíduo, contribuindo para diminuir os problemas ambientais de acúmulo desse material.

O presente trabal ho objetivou avaliar a resposta da soqueira de cana-de-açúcar, durante o terceiro e quarto corte, a partir do efeito residual da escória de siderurgia, quando comparada com o cal cário calcítico, bem como seu efeito em alguns atributos químicos do solo.

\section{MATERIAL E MÉTODOS}

O trabalho foi realizado no campo, na área experimental da F azenda Nossa Senhora A parecida, no município de Ituverava (SP), sob clima mesotérmico, com verão quente e úmido (Cwa), assim classificado pel o sistema Köppen. O L atossolo Vermelho-Amarelo alumínico apresenta as seguintes características químicas: matéria orgânica $=24 \mathrm{~g} \mathrm{dm}^{-3} ; \mathrm{pH}$ em CaCl $20,01 \mathrm{~mol} \mathrm{~L}^{-1}(1: 2,5)=4,6$; P-resina $=5 \mathrm{mg} \mathrm{dm}^{-3} ; \mathrm{K}^{2}=0,4 ; \mathrm{Ca}=8,0 ; \mathrm{Mg}^{2}=5,0$; $\mathrm{H}+\mathrm{Al}=38,0$ todos trocáveis em $\mathrm{mmol}_{\mathrm{c}} \mathrm{dm}^{-3} \mathrm{e}$ $\mathrm{V}=26 \%$, determinados segundo método descrito por Raij et al. (1987).

A escória utilizada é de aciaria, proveniente da siderúrgica produtora de aço do município de Piracicaba (SP), com as seguintes características químicas: $\mathrm{Cu}=0,4 ; \mathrm{Zn}=0,9 ; \mathrm{B}=0,3 ; \mathrm{Mn}=24,7 ; \mathrm{Fe}$ $=261,8$ todos em g kg$~^{-1}$ analisados em extrato de DTPA $0,005 \mathrm{~mol} \mathrm{~L}^{-1} \mathrm{pH} 7,3$, efetuadas conforme o método descrito por Lindsay \& Norwell (1978), exceto o $B$, que foi pelo método da água quente (Bataglia \& Raij, 1990); $\mathrm{CaO}=252 \mathrm{~g} \mathrm{~kg}^{-1} ; \mathrm{MgO}=$ $25 \mathrm{~g} \mathrm{~kg}^{-1}$; PN = 51,4; RE $=79,4$ e PRNT $=41 \%$ (NIAES, 1987). O calcário utilizado foi o calcítico, com as seguintes características: Cão $=372 \mathrm{~g} \mathrm{~kg}^{-1} ; \mathrm{MgO}$ $=27 \mathrm{~g} \mathrm{~kg}^{-1}$; PN $=87,8 ; \mathrm{RE}=73,3$ ePRNT $=64 \%$. A escol ha do cal cário cal cítico deveu-se ao fato de ele apresentar teor de MgO semelhante ao da escória de siderurgia.

Os tratamentos, com quatro repetições, foram dispostos em blocos casualizados, em esquema fatorial $2 \times 4$ (duas fontes decorretivos equatro níveis decorreção), totalizando 32 uni dades experimentais. Além da testemunha (sem correção), as doses de corretivos foram aplicadas, objetivando elevar a saturação por bases aos níveis de 50, 75 e 100 \%, correspondendo, respectivamente, em equivalente $\mathrm{CaCO}_{3}$, a: 0; 1,23; 2,52 e 3,80 t ha-1. Para o cal cário, as doses foram de 1,92; 3,92 e 5,93 t ha-1 e, para a escória de siderurgia, foram de 3,0; 6,12 e 9,27 t ha-1.

Nos tratamentos com calcário, aplicaram-se os micronutrientes $\mathrm{Cu}$, Zn eB nas doses de 5,91; 8,63 e $3,28 \mathrm{~kg} \mathrm{ha}^{-1}$, para o $\vee \%$ igual a 50 , e, assim, proporcionalmente, para os $\mathrm{V}=75 \%$ e $100 \%$. Tal procedimento objetivou equilibrar os teores desses micronutrientes dos tratamentos com cal cário com os da escória, que apresenta em sua composição tais nutrientes. Como fontes, usaram-se os sulfatos de cobre e de zinco e o ácido bórico. Vale destacar que não foram aplicados o Fe e $\mathrm{Mn}$, tendo em vista a reação ácida do solo em estudo, aliada à conhecida baixa resposta da cana-de-açúcar a esses el ementos.

Durante o preparo do solo, aplicaram-sea escória de siderurgia e o cal cário, manual mente, obedecendo à seguinte seqüência: metade, aplicada a lanço, em área total, antes da aração (aivecas), e metade, aplicada a lanço, em área total, depois da aração e antes da gradagem com grade aradora (14 x 32"), objetivando incorporar os corretivos na camada de 0-0,2 m de profundidade. Posteriormente, realizouse o plantio da cana-de-açúcar, variedadeSP 80-1842 (cana de ano), em 03-01-1998, procurando deixar 15 gemas por metro linear de sulco, ficando cada parcela constituída por seis linhas espaçadas de 1,3 $\mathrm{m}$ e com 7,5 m de comprimento, totalizando $58,5 \mathrm{~m}^{2}$ deárea total. As bordaduras entre parcelas e blocos foram de 2,0 e 2,6 m, respectivamente. A área útil da parcela ficou constituída pelas quatro linhas centrais, perfazendo $39,0 \mathrm{~m}^{2}$.

Como adubação básica, aplicaram-se, em todos tratamentos, $1.300 \mathrm{~kg} \mathrm{ha}^{-1}$ da fórmula 04-14-08. Na mesma ocasião, foram aplicados $30 \mathrm{~kg} \mathrm{ha}^{-1}$ de heptacloro, para ocontrole depragas, distribuídos em todas as parcelas, via sulco de plantio. Em cobertura, foram utilizados $60 \mathrm{~kg} \mathrm{ha}^{-1}$ de $\mathrm{N}$ na forma de uréia e $60 \mathrm{~kg} \mathrm{ha}{ }^{-1}$ de $\mathrm{K}_{2} \mathrm{O}$ na forma de cloreto de potássio, incorporados a 0,05 $\mathrm{m}$ de profundidade, aos 42 dias do plantio. Nas soqueiras, foram aplicados $100 \mathrm{~kg} \mathrm{ha}^{-1}$ de $\mathrm{N}$ e $150 \mathrm{~kg} \mathrm{ha}^{-1}$ deK $_{2} \mathrm{O}$, aos 30 dias da emergência dos brotos, incorporados em sulco raso a 0,4 $\mathrm{m}$ da linha plantada ea 0,05 m de profundidade. Utilizouse o método químico para o controle das plantas daninhas, com herbicida pós-emergente sistêmico.

Na soqueira da cana-de-açúcar (3o e $4^{\circ}$ corte), foram avaliados o perfil hamento ea altura aos $90 \mathrm{e}$ 120 dias da emergência do broto, respectivamente, em 1,5 m de cada linha da parcela útil. O estado nutricional das plantas foi avaliado por meio de amostragens de fol has (+3) (Gallo et al., 1968) e das folhas totais da parte aérea, 120 e 345 dias após a emergência dos brotos, respectivamente. As determinações analíticas foram feitas, conforme método de Sarruge \& Haag (1974). A colheita de colmos industrializáveis da soqueira de cana-deaçúcar (30 e $4^{\circ}$ corte) foi efetuada na área útil, aos 345 dias da emergência dos brotos das soqueiras, pelo método de col heita via cana crua. Nesta mesma ocasião, avaliou-se o peso unitário de col mos obtido da amostragem de 20 colmos por área útil, bem como o número de colmos por metro linear, obtido em 1,5 m de cada linha da parcela útil. Vale ressaltar que os resultados dos dois primeiros cortes, que avaliaram o efeito imediato da escória desider urgia no sistema solo-planta, foram apresentados no trabalho de Prado et al. (2001b). 
Aos 36 e 48 meses da aplicação dos corretivos, ou seja, na época da col heita das soqueiras de 30 e 40 corte, foram retiradas 15 amostras simples de solo por parcela para compor a amostra composta, utilizando-se de um trado holandês. A amostragem foi efetuada nas camadas de 0,0-0,2; 0,2-0,4 e 0,40,6 m de profundidade. As análises químicas dessas amostras ( $\mathrm{pH}$ em $\mathrm{CaCl}_{2}$ eH + Al, Ca eMg trocáveis) foram efetuadas, conformemétodo descrito por Raij et al. (1987).

De acordo com o método de Pimentel-Gomes (1985), foram realizadas as análises de variância conjunta e, para isso, foram sel ecionadas e consideradas as variáveis cujos quadrados médios residuais não diferiram em mais de sete vezes de uma safra para outra. Os dados foram submetidos também à análise de regressão $(P<0,05)$, realizada pelo programa estatístico SAS (1985).

\section{RESULTADOS E DISCUSSÃO}

\section{Atributos químicos do solo}

A análise conjunta dos valores de $\mathrm{pH}$, dos teores de $\mathrm{Ca}, \mathrm{Mg}, \mathrm{H}+\mathrm{Al}$ e do valor $\mathrm{V} \%$ não mostrou interação $(P<0,05)$ da época de amostragem do solo e os níveis de correção do tratamento escória de siderurgia e cal cário nas profundidades avaliadas, exceto com os teores de $\mathrm{Ca}$, quando se aplicou calcário na profundidade de 0-0,2 m (dados não apresentados). Verificou-se que, na primeira amostragem, a dose dos corretivos equivalentes a $1,23 \mathrm{t} \mathrm{ha}^{-1}$ de $\mathrm{CaCO}_{3}$ apresentou o teor de Ca maior que a dose de 2,52 tha-1 de $\mathrm{CaCO}_{3}$, enquanto, na segunda amostragem, estas doses não provocaram diferenças nos atributos químicos avaliados. A ausência de interação evidencia queas variações nas características químicas do solo, dependendo dos níveis dos corretivos utilizados, foram proporcionalmente semelhantes nas diferentes épocas de amostragens.

Verificaram-se ajustes $(P<0,05)$, semelhantes para os dois corretivos, quanto ao $\mathrm{pH}$, e $\mathrm{Ca}$ e $\mathrm{Mg}$ trocáveis e redução no $\mathrm{H}+\mathrm{Al}$ trocável em duas profundidades, 0,0-0,2 e 0,2-0,4 m, com exceção do Mg trocável, na profundidade de 0,4-0,6 m, em que o valor $F$ não foi significativo $(P>0,05)$ (Figura 1$)$. Resultados semel hantes foram obtidos por Ribeiro et al. (1986), quando compararam a escória de siderurgia e o calcário na neutralização da acidez do solo.

Observou-se, ainda, que, para as maiores doses dos corretivos, a escória foi superior ao calcário cal cítico quanto à el evação nos teores de M g trocável do solo, especialmente na camada de 0,2-0,4 m. Entretanto, em sol os com teor de Mg trocável inferior a 3,6 $\mathrm{mmol}_{\mathrm{C}} \mathrm{dm}^{-3}$, como é o caso do presente trabal ho, Kidder \& Gascho (1977) recomendaram a aplicação complementar de $40 \mathrm{~kg} \mathrm{ha}^{-1}$ de $\mathrm{Mg}$, em pré-plantio, em área na qual será utilizada a escória de siderurgia.

Os aumentos do $\mathrm{pH}$ e $\mathrm{Ca}$ e a redução do $\mathrm{H}+\mathrm{Al}$ na camada de 0,2-0,4 e 0,4-0,6 m de profundidade evidenciam os efeitos positivos da aplicação da escória de siderurgia e do cal cário na subsuperfície, abaixo da camada mobilizada na qual foram incorporados (Figura 1). Na literatura, têm sido freqüentemente relatados estudos que confirmam a baixa ação do cal cário no perfil do sol o (K och \& Estes, 1986), enquanto outros evidenciam a neutral ização da aci dez em subsuperfície (Oliveira \& Pavan, 1996). Morelli et al. (1992) também observaram este fato na reação do solo em subsuperfície, abaixo da camada mobilizada, em área cultivada com canade-açúcar submetida à aplicação de cal cário.

Os efeitos em profundidade dos corretivos foram proporcionais às doses aplicadas. Esse efeito no perfil do sol o pode receber contribuição de natureza física, pela descida de partículas nos canais deixados pela decomposição de raízes (Pearson et al., 1962); ou de natureza química, seja pela formação de pares entre bases (Ca e Mg) e ácidos orgânicos de alta solubilidade, os quais estariam permitindo o carreamento destes pares às camadas subsuperficiais do perfil (Miyazawa et al., 1993; Franchini et al., 1999; Miyazawa et al., 2001), seja pela adubação nitrogenada, que pode levar à formação de sais solúveis de nitrato de cálcio, os quais podem ser percolados pel o movimento descendente da água no perfil do solo (Blevins et al., 1977).

Observou-se, como era esperado, um acréscimo na saturação por bases do solo nas três profundidades anal isadas, dependendo da aplicação dos corretivos (Figura 2). Assim, o aumento dessa variável nas camadas subsuperficiais confirma a ação do calcário no perfil do solo, discutido anteriormente. Verificou-se, ainda, que a saturação por bases nas camadas subsuperficiais com aplicação de escória foi superior à do cal cário, especialmente na maior dose aplicada. Na camada de 40-60 cm, a saturação por bases atingiu 47 e $38 \%$ respectivamente, quando foram aplicados a escória e o cal cário, indicando maior mobilidade do silicato comparado ao carbonato.

Os resultados favoráveis na reação do solo dos materiais corretivos incorporados após 36-48 meses mostram o efeito residual dos corretivos utilizados. Na literatura, estudos semel hantes com uso do cal cário demonstram esse efeito residual em solo cultivado com cana-de-açúcar, podendo prol ongar até 33 meses (Silva et al., 1991) ou até 56 meses, especialmente em sol os arenosos (Orlando Filho et al., 1996).

Para a escória de siderurgia, inexistem estudos realizados no Brasil que tratam do efeito residual em área cultivada com cana-de-açúcar. Entretanto, os resultados iniciais (dois primeiros anos agrícolas), descritos por Prado et al. (2001b), mostram que a 

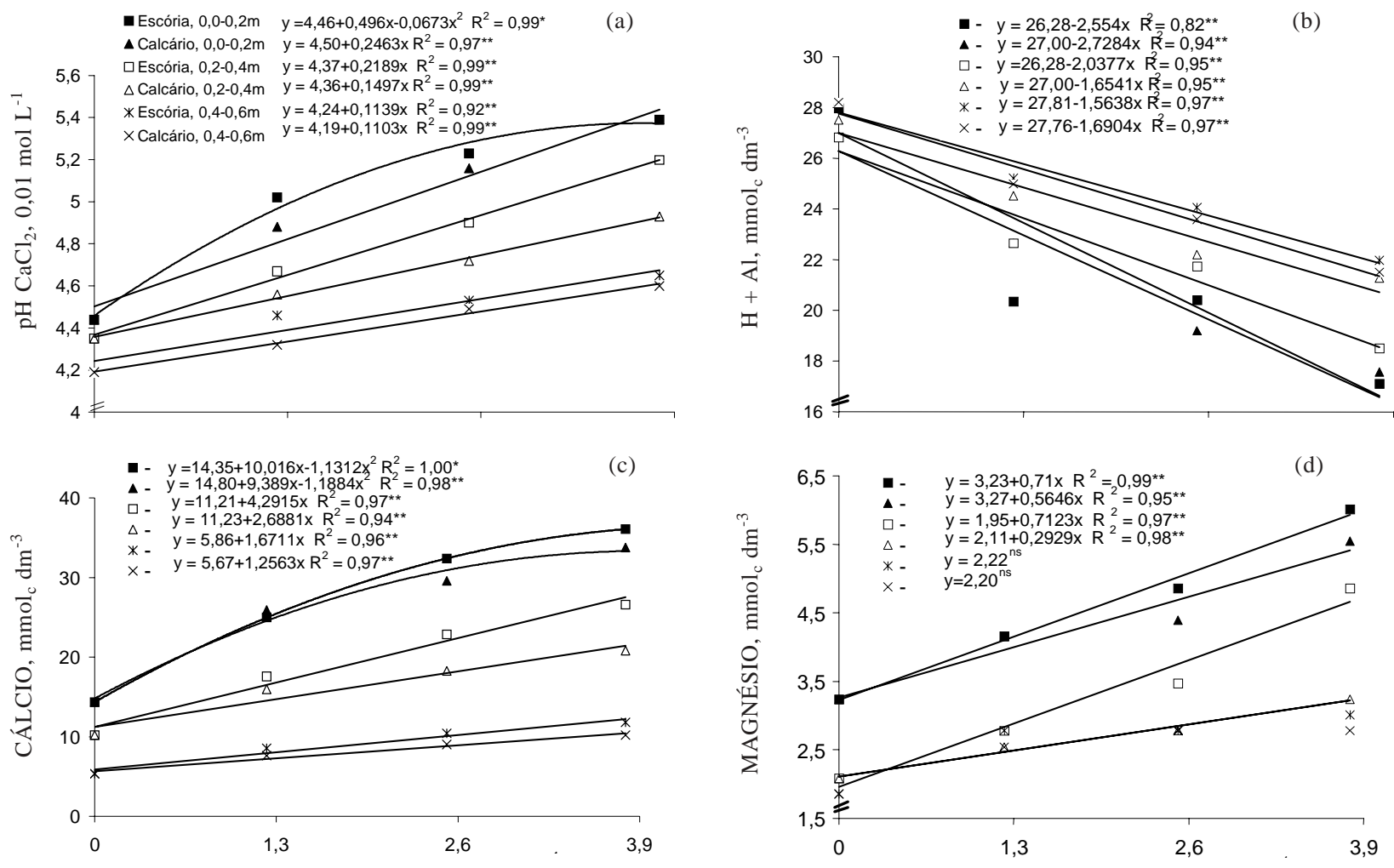

Figura 1. Atributos quími cos em diferentes profundidades do solo, considerando as doses de corretivos da acidez do solo: (a) pH $\mathrm{CaCl}_{2}$, (b) $\mathrm{H}+\mathrm{Al}$, (c) cálcio trocável, (d) magnésio trocável.

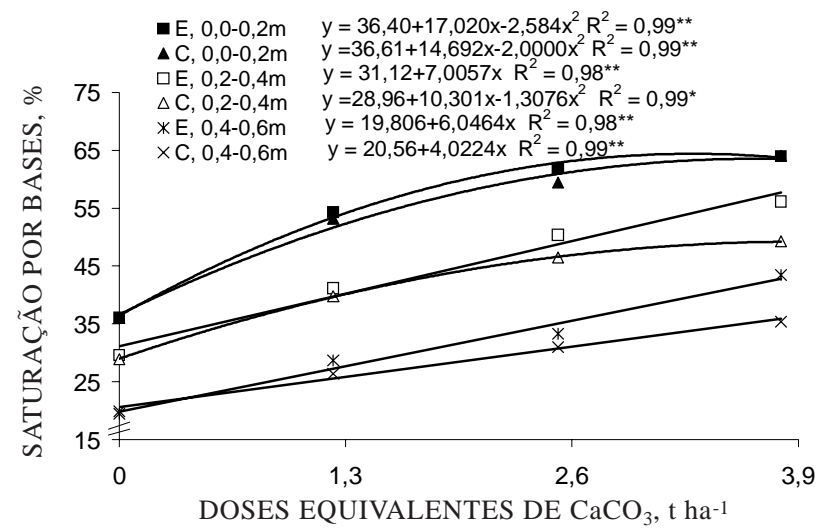

Figura 2. Saturação por bases em diferentes profundidades, considerando as doses de corretivos da acidez do solo.

reação máxima dos corretivos atingiu, aos 12 meses e na dose máxima dos corretivos, a saturação por bases (camada de $0-20 \mathrm{~cm}$ ), em média, $82 \%$ durante os primeiros 24 meses após sua aplicação. J á aos 36-48 meses, a saturação por bases manteve-se próxima a $64 \%$ para a mesma dose de corretivos (média de calcário e escória) (Figura 2). Portanto, nota-se efeito residual semel hante do cal cário e da escória na reação do solo.
Em Taiwan, a escória de siderurgia aplicada em áreas cultivadas com arroz tem apresentado efeito residual prolongado (Lian, 1992), bem como, no Havaí, em um sistema de rotação de culturas (canade-acúcar, milho ecapim-desmodium), com um efeito residual favorável durantecinco anos, independentemente do pH inicial do solo $(5,5 ; 6,0$ ou 6,5) (Khalid et al., 1978).

\section{Nutrição e desenvolvimento da soqueira da cana-de-açúcar}

Pela análise conjunta dos resultados, observouse que não houve significância $(P<0,05)$ para a interação dos diferentes cortes da cana-de-açúcar e os níveis de correção, graças à aplicação da escória de siderurgia e do calcário nas variáveis altura, perfil hamento, número de col mos por metro linear, peso unitário de colmo e produção de colmos da soqueira de cana-de-açúcar.

As concentrações foliares para os macronutrientes (fol ha +3 ), aos quatro meses da emergência do broto (dados não apresentados), não foram afetadas pela aplicação dos corretivos. No final, as concentrações deCa, Mge P da parteaérea (fol has totais) na época da col heita foram afetadas de forma quadrática pel os corretivos, enquanto as concentrações de $\mathrm{Mg}$ e o $\mathrm{P}$ para a escória de siderurgia foram lineares (Figura 3). 

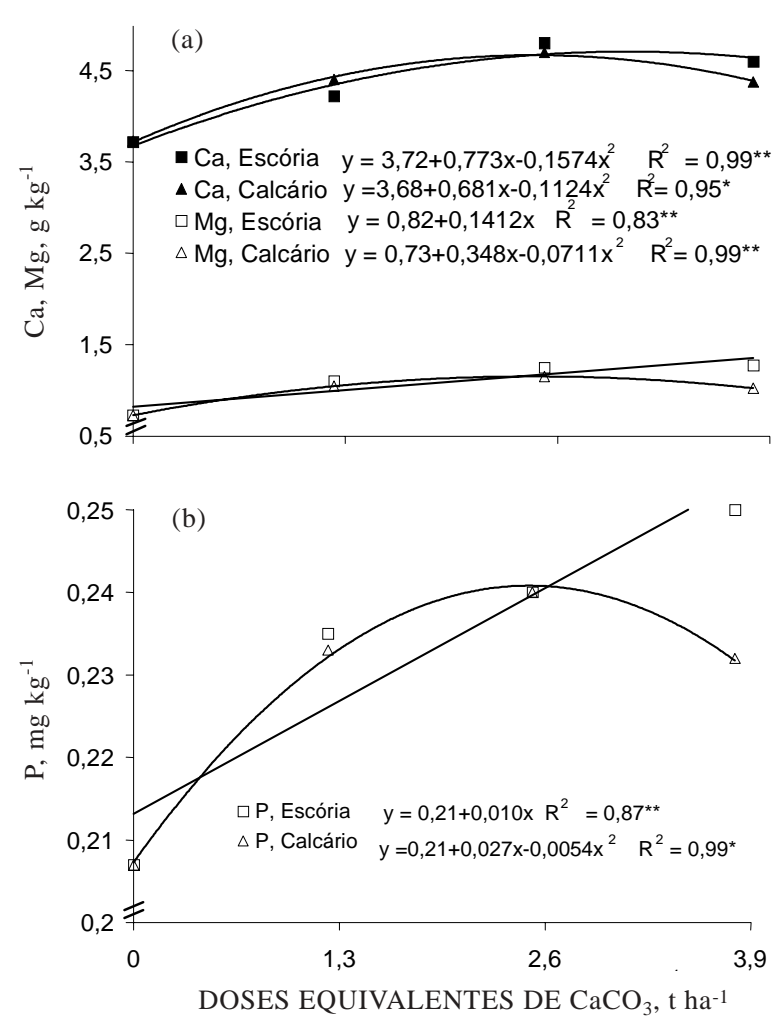

Figura 3. Teores de nutrientes nas folhas da soqueira de cana-de-açúcar amostrados na colheita, considerando as doses de corretivos da acidez do solo: (a) cálcio e magnésio, (b) fósforo.

Tendo em vista o efeito positivo dos materiais corretivos na produtividade da cana-de-açúcar (Figura 4b), eram esperadas diferenças no estado nutricional das plantas pela diagnose foliar (fol ha +3 ) nas diferentes doses de corretivo.

Duas hipóteses podem explicar o ocorrido: a primeira refere-se ao efeito diluição, ou seja, a concentração dos nutrientes é diluída com o maior crescimento da planta, fato amplamenterelatado na literatura (J arrell \& Beverly, 1981), e por ter a aplicação dos corretivos promovido maior crescimento da planta (altura), tal ocorrência é possível; a segunda hipótese, mais provável, refere se ao tipo de folha amostrada (+3), uma vez que existem outras recomendações como a fol ha +1 , que é a mais utilizada nas áreas de produção de canade-açúcar em nível mundial, segundo OrlandoFilho \& ZambelloJ únior (1983). No Havaí, utilizam-seas fol has $+3,+4,+5$ e +6 (o ponteiro éconsiderado como a folha +1 ) (Clements, 1959) e, em Porto Rico, as folhas +4 , +5 e +6 (Samuels et al., 1960).

Vale destacar que a amostragem das folhas das plantas pode ter sido realizada precocemente, aos quatro meses de idade, o que pode ter interferido nos resultados.

Observam-se, ainda, as divergências quanto à parte da planta a ser amostrada. Sabendo que o tipo defol ha definea sua idade, constituindo, por sua vez, uma fonte de variação importante, tal fato pode influir nas interpretações do estado nutricional da planta.

O crescimento inicial da soqueira da cana-deaçúcar sofreu interação significativa, visto que a aplicação da escóría proporcionou um efeito quadrático, e o calcário, um efeito linear na altura da planta. Para o perfilhamento, o efeito foi linear com os dois materiais corretivos (Figura 5). Gascho (1978) também obteve incremento na al tura da canade-açúcar com a aplicação da escória de siderurgia. Respostas lineares maiores pela aplicação da escória de siderurgia, em relação ao calcário, no perfilhamento da cana-de-açúcar (1o e 2o corte), foram obtidas em experimentos em condições de vaso em um N eossol o Quartzarênico (Prado \& Fernandes, 2000a) e em um Latossolo Vermel ho distrófico (Prado \& Fernandes, 2001a).

Este maior crescimento da soqueira da cana-deaçúcar, com a aplicação dos materiais corretivos (Figura 5), resultou em mai or número de col mos por metro linear (Figura 4a) e produção de colmos (Figura 4b). Ressalte-se que o efeito linear pela aplicação da escória de siderurgia na produção de col mos é explicado pel o mai or número de col mos por metrolinear industrializáveis na época da col heita, visto que os corretivos proporcionaram aumento

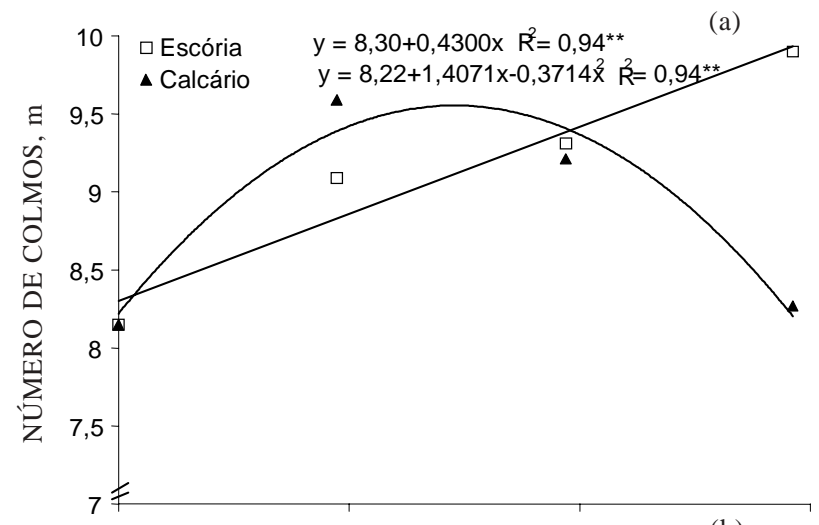

(b)

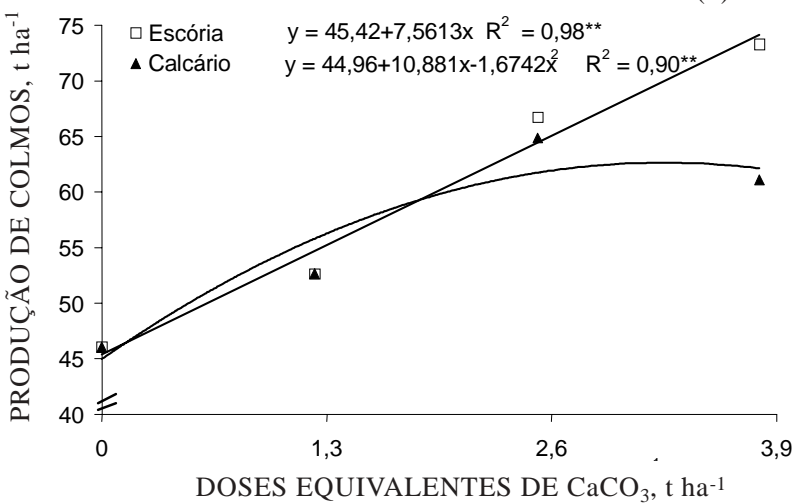

Figura 4. Produção da soqueira de cana-de-açúcar, considerando as doses de corretivos da acidez do solo: (a) número decolmos, (b) produção decolmos. 
linear semelhante para o peso unitário de colmos (Figura 6). Esta estreita relação do número e da produção de colmos da cana-de-açúcar e aplicação da escória de siderurgia também foi reportada por Elawad et al. (1982), na Flórida, USA, e por Prado \& Fernandes (2001b), em SãoPaulo, durante os dois primeiros cortes da cana-de-açúcar, sendo ambos experimentos realizados em condições de campo. Acredita-se que o maior perfilhamento e o número de colmos industrializáveis com a aplicação da escória de siderurgia sejam devidos à presença do silício, visto que oSi incrementa o número de brotos em cana-de-açúcar, embora essefenômeno não esteja total mente esclarecido (Plucknett, 1971).

E feitos semel hantes no aumento da produção da cana-de-açúcar foram obtidos por Orlando Filho et al. (1990), quando aplicaram o calcário, e por Anderson et al. (1987), quando utilizaram a escória de siderurgia. Saliente-se que o efeito residual da escória de siderurgia no aumento da produção da cana-de-açúcar é mais importante nas soqueiras, quando comparado com a cana-planta (Wong, 1971), tendo Anderson et al. (1991) observado (média de três cortes), reduções de 45 e 28 \% na produção de colmos das soqueiras nas parcelas sem e com a apli cação da escória desiderurgia, respectivamente.

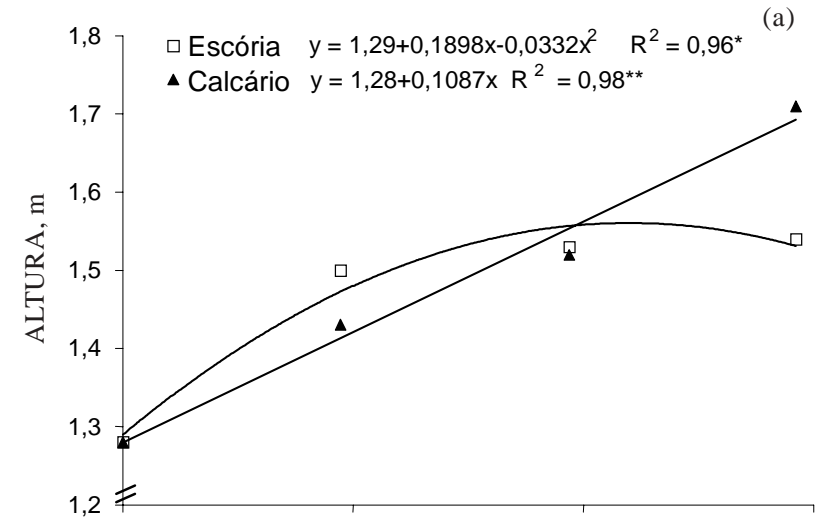

(b)

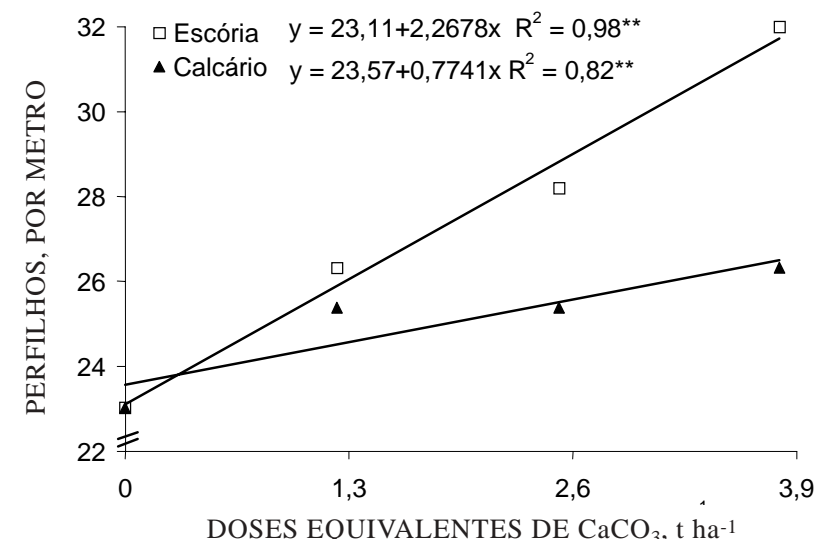

Figura 5. Crescimento da soqueira de cana-deaçúcar, consi derando as doses de corretivos da acidez do solo: (a) altura, (b) número de perfilhos por metro.

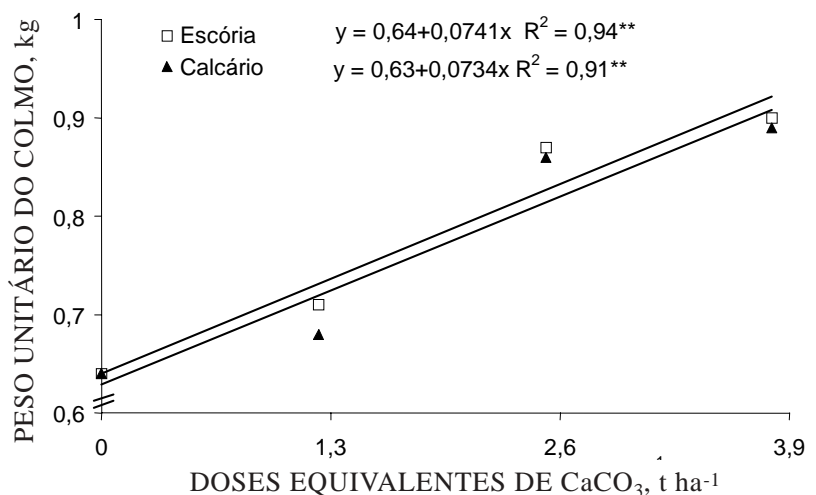

Figura 6. Peso unitário de colmos da soqueira de cana-de-açúcar, considerando as doses de corretivos da acidez do solo.

As respostas positivas à aplicação do cal cário ou da escória de siderurgia mostram a sensibilidade da cana-de-açúcar (variedade SP 80-1842) à acidez do solo, indicando, assim, a necessidade dessa prática para o incremento na produção. Por outro lado, existem relatos na literatura que indicam que a cultura apresenta alta tolerância à reação ácida do solo (Vargas, 1981; Azevedo \& Sarruge, 1984).

Outro ponto a ser destacado é que a aplicação do calcário para a dose equivalente em 3,9 t ha-1 (F igura 4b) resultou em decréscimo na produção de colmos, enquanto a mesma dose equival ente para a escória de siderurgia, ao contrário, continuou aumentando a produção de colmos. Resultados semel hantes foram descritos por Tamini \& Matsuyama (1972) e por Prado\& Fernandes (2001b), que observaram um efeito depressivo na produção pelo excesso de calcário, o que não ocorreu com a escória de siderurgia. Esta apresenta silício na sua composição, ea cana-de-açúcar, sabidamente, éuma das gramíneas que mais extrai silício do solo. Desta forma, o silício, embora não seja considerado essencial, é benéfico à cana-de-açúcar, já que sua aplicação leva a incrementos na produção (Raid et al., 1992), reduzindo a taxa de senescência foliar, de forma que as folhas da cana-de-açúcar ficam fotossinteticamente ativas por mais tempo (Prado \& Fernandes, 2000b). A aplicação do calcário não tem esse efeito, por não apresentar silício na sua composição.

Anderson et al. (1987) e Elawad et al. (1982) também obtiveram um efeito positivo da aplicação da escória de siderurgia na produção da cana-deaçúcar, porém, para doses bem acima da maior dose utilizada no experimento $\left(9,27 \mathrm{t} \mathrm{ha}^{-1}\right)$, o efeito passou a ser quadrático, indicando um efeito depressivo em doses acima de $15 \mathrm{t} \mathrm{ha}^{-1}$.

Obteve-se uma estreita relação entre a produção de colmos e a média da saturação por bases do solo nas profundidades de 0,0-0,2 e 0,2-0,4 m (Figura 7). Observou-se uma relação linear da produção de 
colmos com a saturação por bases do solo determinada conforme a aplicação da escória de siderurgia, indicando resposta da cana-de-açúcar a doses mai ores desse corretivo.

Avaliando o tratamento calcário, houve uma relação quadrática, estimando-se que o máximo rendimento de colmos seria obtido com $61 \%$ da saturação por bases, na profundidade de 0,0-0,2 m (Figura 7a). Esse valor é próximo ao sugerido por Raij et al. (1996) para essa cultura, no estado de São Paulo. Da mesma forma, na profundidade de 0,2-0,4 m, observou-se uma relação direta entre a saturação por bases e a produção de col mos, para os dois corretivos, bem como uma relação quadrática para o cal cário com o máximo na saturação por bases de 62 \% (Figura 7b). A resposta positiva da correção do solo em subsuperfície na produção de colmos da cana-de-açúcar também foi reportada por Prado et al. (1998). U Uma das causas deste efeito, provavelmente, seria pelo papel do cálcio no crescimento radicular (Ritchey et al., 1982), tendo em vista que a aplicação dos corretivos aumentou linearmente os teores de Ca em subsuperfície (Figura 1).

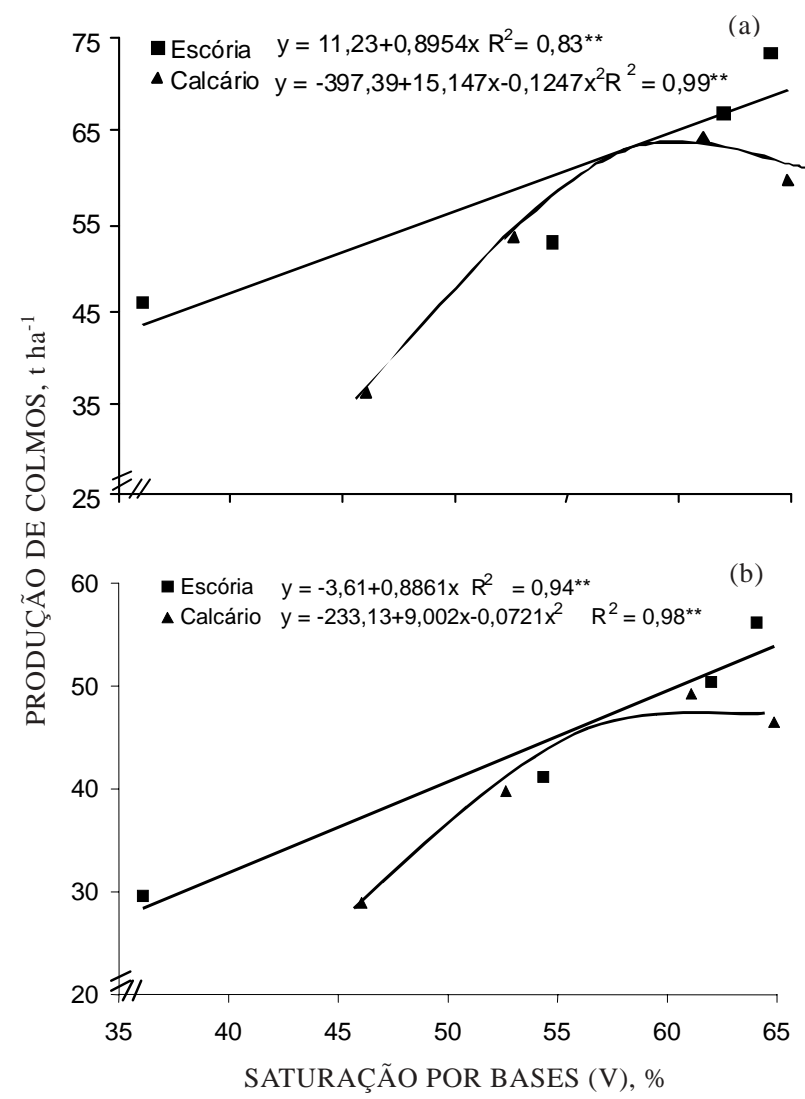

Figura 7. Produção da soqueira de cana-de-açúcar, consi derando a saturação por bases obtida pela aplicação de corretivos da acidez do solo: (a) camada de 0-0,20 m, (b) camada de 0,2-0,4 m. (Dados médios da soquei ra de terceiro e quarto corte).
Vale salientar que a variedade decana-de-açúcar utilizada (SP 80-1842), pela interferência do melhoramento genético, apresenta um sistema radicular mais bem distribuído e mais abundante na camada de 0,2-0,4 m, sendo 20 e $28 \%$ superior às variedades IAC 873396 e RB 855336, respectivamente (Vasconcel os, 2000).

\section{CONCLUSÕES}

1. O calcário calcítico e a escória de siderurgia promoveram efeito residual benéfico nos atributos de acidez do solo após 48 meses da aplicação.

2. A maior dose de calcário (equivalente a $3,8 \mathrm{t} \mathrm{ha}^{-1}$ de $\mathrm{CaCO}_{3}$ ) causou efeito depressivo no perfil hamento, no número de col mos industrial izáveis e na produção da cana-de-açúcar, fato não observado com o uso da escória de siderurgia.

3. A aplicação da escória de siderurgia e do calcário, em pré-plantio, promoveu efeito residual positivo na produção da soqueira da cana-de-açúcar.

\section{AGRADE CIMENTOS}

À FAPESP, pelo auxílio financeiro concedido (Proc.97/05888-5) durante os dois primeiros anos agrícolas, e à Fazenda Nossa Senhora Aparecida, pelo apoio durante toda a fase experimental .

\section{LITE RATURA CITADA}

AMARAL, A.S.; DEFELIPO, B.V.; COSTA, L.M. \& FONTES, M.P.F. Liberação de $\mathrm{Zn}, \mathrm{Fe}, \mathrm{Mn}$ e $\mathrm{Cd}$ de quatro corretivos da acidez eabsorção por alface em dois sol os. Pesq. Agropec. Bras., 29:1351-1358, 1994.

ANDERSON, D.L.; J ONES, D.B. \& SNYDER, G.H. Response of a rice-sugarcane rotation to calcium silicate slag on Everglades Histosols. Agron. J ., 79:531-535, 1987.

ANDERSON, D.L.; SNYDER, G.H. \& MARTIN, F.G. Multi-year response of sugarcaneto cal cium silicateslag on Everglades Histosols. Agron. J ., 83:870-874,1991.

AZEVEDO, D.F. \& SARRUGE, J .R. Alumínio na produção de matéria seca em diferentes cultivares de cana-de-açúcar (Saccharum spp). Saccarum, 34:17-23,1984.

BATAGLIA, O.C. \& RAIJ , B. Van. Eficiência de extratores na determinação de boro em solos. R. Bras. Ci. Solo,14:2531,1990.

BLEVINS, R.L.; THOMAS, G.W. \& CORNELIUS, P.L. I Influence of no-tillage and nitrogen fertilization on certain soil properties after 5 years of continuous corn. Agron. J ., 69:383-386, 1977. 
CLEMENTS, H.F. Sugarcane nutrition and culture. Lucknow, Indian Institute Research, 1959. 89p.

ELAWAD, S.H.; GASCHO, G.J . \& STREET, J J. . Response of sugarcane to silicate source and rate. I. Growth and yield. Agron. J ., 74:481-483, 1982.

FRANCHINI, J.C., MALAVOLTA, E., MIYAZAWA, M. \& PAVAN, M.A. Alterações químicas em solos ácidos após a aplicação de resíduos vegetais. R. Bras. Ci. Solo, 23:533542, 1999.

GALLO, J .R.; HIROCE, R. \& ALVAREZ, R. Levantamento do estado nutricional de canaviais de São Paulo pela análise foliar. Bragantia, 27:365-382, 1968.

GASCHO, G.J . Response of sugarcane to cal cium silicate slag. I. Mechanisms of response in Florida. Soil Crop Sci. Soc. Fla. Proc., 37:55-58,1978.

J ARRELL, W.M. \& BEVERLY, R.B. The dilution effect in plant nutrition studies. Adv. Agron., 34:197-224, 1981.

KATO, N. \& OWA, N. Dissolution of slag in water and calcium chloride solution: Effects of solution $\mathrm{pH}$ and calcium concentration on solubilities of slags. J apan J . Soil Sci. Plant Nutr., 67:626-32, 1996.

KHALID, R.A.; SILVA, J.A. \& FOX, R.L. Residual effects of calcium silicate in tropical soil. I-Fate of applied silicon during five years cropping. Soil Sci. Soc. Am. J ., 42:89-94, 1978.

KIDDER, G. \& GASCHO, G.J. Silicate slag recommended for specified conditions in Florida. Gainesville, University of Florida,1977. 2p. (Agronomy Factors, 65)

KOCH, D.W. \& ESTES, G.O. Liming rate and method in relation to forage establishment - crop and soil chemical responses. Agron. J ., 78:567-571, 1986.

LIAN, S. Effect of continued application of silicate slag under the double rice-based cropping system. In: INTERNATIONAL SYMPOSIUM ON PADDY SOILS, 1., Nanjing, 1992. Proceedings. Nanjing-China, Academia Sinica, 1992. p.222-223.

LINDSAY, W.L. \& NORWELL, W.A. Development of a DTPA soil test for zinc, iron, manganese and copper. Soil Sci. Soc. Am. J ., 42:421-428, 1978.

MIYAZAWA, M., PAVAN, M.A. \& CALEGARI, A. Efeito de material vegetal na acidez do solo. R. Bras. Ci. Solo, 17:411416, 1993.

MIYAZAWA, M., FRANCHINI, J.C.; VILA, F.J .G. \& PAVAN, M. Rapid transformations of plant water soluble organic compounds in relation to cation mobilization in an acid Oxisol. Plant Soil., 231:55-63, 2001.

MORELLI,J .L.; DALBEN, A.E.; ALMEIDA,J .O.C.\& DEMATTÊ J .L.I. Cal cário e gesso na produtividade da cana-de-açúcar e nas características químicas de um Latossolo de textura média álico. R. Bras. Ci. Solo, 16:187-194, 1992.

NATIONAL INSTITUTE OF AGRO-ENVIRONMENTAL SCIENCES - NIAES. Official methods of analysis of fertilizers. Tsukuba, Fundation Nohrin Kohsaikai, 1987. $124 p$.

OLIVEIRA, E.L. \& PAVAN, M.A. Control of soil acidity in notillage system for soybean production. Soil Till. Res., 38:4757, 1996.
ORLANDO FILHO, J . \& ZAMBELLO J ÚNIOR, E. Diagnose foliar. In: ORLANDO FILHO, J ., ed. Nutrição e adubação da cana-de-açúcar no Brasil. Piracicaba, PLANALSUCAR, 1983. p.125-152.

ORLANDO FILHO, J .; ROSSETTO, R. \& MURAOKA, T. Efeito residual da calagem (56 meses) sobre os valores de $\mathrm{pH}$, cálcio e magnésio do sol o. STAB Açúcar, Álcool Subp., 14:1921, 1996.

ORLANDO FILHO, J .; SILVA, L.C.F. \& MANOEL, L.A. Fontes de calcário aplicadas em área total e sulco de plantio em cana-de-açúcar. STAB Açúcar, Álcool Subp., 9:11-16, 1990.

PEARSON, R.W.; ABRUNA, F. \& VICE-CHANCES, J . Effect of lime and nitrogen applications on downward movements of calcium and magnesium in two humid soils of Puerto Rico. Soil Sci., 93:77-82, 1962.

PIMENTEL-GOMES, F. Curso de estatística experimental. São Paulo, Nobel, 1985. 466p.

PLUCKNETT, D.L. The use of soluble silicates in Hawaii agriculture. Univ. Queenl. Pap., 1:203-223, 1971.

PRADO, H.; ROSSETO, R. \& LANDELL, M.G.A. Instituto Agronômico de Campinas propõe classificação de solos adaptada para a cultura da cana-de-açúcar. STAB Açúcar, Álcool Subp., 16:13, 1998.

PRADO, R.M. \& FERNANDES, F.M. Eficiência da escória de siderurgia em Areia Quartzosa na nutrição e na produção de matéria seca de cana-de-açúcar cultivada em vaso. STAB Açúcar, Álcool Subp., 18:36-39, 2000a.

PRADO, R.M. \& FERNANDES, F.M. Escória de siderurgia e calcário na taxa de fol has senescentes da cultura da canade-açúcar. R. Agric., 75:311-321, 2000b.

PRADO, R.M. \& FERNANDES, F.M. Eficiência da escória de siderurgia em Latossolo Vermelho na nutrição e na produção de matéria seca de cana-de-açúcar cultivada em vaso. STAB Açúcar, Álcool Subp., 19:26-29, 2001 a.

PRADO, R.M. \& FERNANDES, F.M. Resposta da cana-de-açúcar à aplicação da escória de siderurgia como corretivo de acidez do solo. R. Bras. Ci. Solo, 25:201-209, 2001b.

PRADO, R.M.; FERNANDES, F.M . \& NATALE, W. Usoagrícola da escória de siderurgia no Brasil: estudos na cultura da cana-de-açúcar. J aboticabal, FUNEP, 67p. 2001.

RAID, R.N.; ANDERSON, D.L. \& ULLOA, M.F. Influence of cultivar and amendment of soil with calcium silicate slag on foliar disease development and yield of sugar cane. Crop Protec., 11:84-88, 1992.

RAIJ , B. van; CANTARELLA, H.; QUAGGIO, J .A \& FURLANI, A.M.C., eds. Recomendações de adubação e calagem para o estado deSão Paulo. 2.ed. Campinas, Instituto Agronômico deCampinas \& Fundação IAC, 1996. 255p. (Bol etim Técnico, 100)

RAIJ , B. van; QUAGGIO, J .A. \& CANTARELLA, H. Análise química do solo para fins de fertilidade. Campinas, Fundação Cargill, 1987. 107p.

RIBEIRO, A.C.; FIRME, D.J . \& MATOS, A.C.M. Avaliação da eficiência de uma escória de aciaria como corretivo da acidez. R. Ceres, 33:242-248, 1986. 
RITCHEY, K.D.; SILVA, J .E. \& COSTA, U.F. Calcium deficiency in clayey B horizons of savanna Oxisols. Soil Sci., 133:378382, 1982.

SALATA,J .C.; SANTOS, E. \& DEMATTÊ, J .L.I . Ação do cal cário e gesso em solos de baixa fertilidade e na recuperação de soqueiras de cana-de-açúcar. STAB Açúcar, Álcool Subp., 14:19-22, 1995.

SAMUELS, G.; LANDRAU J R., P. \& ALERS, S. I nfluence of height of cane and leaf stage at time of sampling on leaf nutrients contents. J . Agr. Univer. Puerto Rico, 44:11-15, 1960.

SARRUGE, J .R. \& HAAG, H.P. Análise química em plantas. Piracicaba, Escola Superior de Agricultura "Luiz de Queiroz", 1974. 56p.

SAS INSTITUTE. SAS U ser's guide: statistics. 5.ed. Cary, 1985. 956p.
SILVA, L.C.F.; ORLANDO FILHO, J .; LAVORENTTI, N.A. \& MANOEL, L.A. Efeitos de diferentes tipos de calcário em algumas propriedades químicas do solo. STAB Açúcar, Álcool Subp., 9:16-21,1991.

TAMINI, Y.N. \& MATSUYAMA, D.T. The effect of calcium silicate and calcium carbonate on growth of sorghum. Agric. Digest, 25:37-44, 1972.

VARGAS, J .T.D. Efeito na cultura de cana-de-açúcar da aplicação de calcário como corretivo e adubo em solo de cerrado. Piracicaba, Escola Superior de Agricultura Luiz deQueiroz, 1981. 77p. (Tese de Mestrado)

VASCONCELOS, A.C.M. As raízes da cana-de-açúcar. STAB Açúcar, Álcool Subp., 18:26-26, 2000.

WONG, Y.C. The residual effect of calcium silicate application of sugarcane growth. Mauritius Sugar Ind. Res. Inst., Ann. Rep., 18:63-68, 1971. 